\title{
Medida de regularidade do espaçamento de plantas de milho em diferentes sistemas de manejo
}

\author{
Lindolfo Storck ${ }^{1}$, Alcir J. Modolo², Betania Brum ${ }^{3}$, Emerson Trogello ${ }^{4}$, \\ Marcia F. Franchin ${ }^{5} \&$ Paulo F. Adami ${ }^{6}$
}

\section{Palavras-chave:}

dossel de plantas uniformidade de distribuição controle de qualidade

\begin{abstract}
R E S U M O
Objetivou-se, neste estudo, obter a medida de regularidade (MR) do espaçamento entre plantas de milho e o número ótimo de plantas em sequência para estimar a MR em diferentes sistemas de manejo. No primeiro estudo foram avaliados os efeitos de quatro manejos da palha em parcelas principais, dois mecanismos sulcadores (disco duplo e haste sulcadora) em subparcelas e duas velocidades da máquina $\left(4,5\right.$ e 7,0 $\left.\mathrm{km} \mathrm{h}^{-1}\right)$ em subsubparcelas e no segundo se avaliaram quatro intensidades de pastejo em parcelas principais além de dois mecanismos sulcadores, em subparcelas. Foram avaliadas a produção de grãos e a distância entre as 40 plantas consecutivas no primeiro estudo e 18 plantas no segundo. Em cada unidade experimental foi calculada a média da distância entre as plantas e a MR. Procedeu-se à análise de variância com vista à produção de grãos, à média das distâncias e à MR, segundo o modelo de cada estudo. Para estimar a MR é suficiente usar as medidas das distâncias entre 26 plantas de milho para estudo de manejo de palha e 16 plantas de milho para o estudo do pastejo. A estatística, chamada medida de regularidade, pode ser usada para avaliar a exatidão de distribuição das sementes ou plantas de milho, passível de ser aplicada nos casos de laudo técnico de funcionamento de semeadoras.
\end{abstract}

\section{Measures of the regularity of spacing of maize plants under different management systems}

Protocolo 384.13 - 05/12/2013 • Aprovado em 22/08/2014 • Publicado em 01/01/2015

${ }^{1}$ PPGA/UTFPR. Pato Branco, PR. E-mail: lindolfostorck@gmail.com (Autor correspondente)

${ }^{2}$ PPGA/UTFPR. Pato Branco, PR. E-mail: alcir@utfpr.edu.br

${ }^{3}$ PPGA/UTFPR. Pato Branco, PR. E-mail: bbufsm@gmail.com

${ }^{4}$ IFGoiano. Morrinhos, GO. E-mail: etrogello@yahoo.com.br

${ }^{5}$ PPGA/UTFPR. Pato Branco, PR. E-mail: marciafranc@hotmail.com

${ }^{6}$ UTFPR. Dois Vizinhos, PR. E-mail: pauloadami@utfpr.edu.br 


\section{INTRODUÇÃo}

O número médio de sementes por metro linear é facilmente calculado a partir dos conhecimentos da distância percorrida, da massa total de sementes semeadas no percurso e da massa de cem sementes. No entanto, a regularidade do espaçamento entre as sementes distribuídas ou entre as plantas estabelecidas, é igualmente importante para uma boa formação do dossel, aproveitamento eficiente de luz, água e nutrientes e para alcançar o potencial produtivo da cultura (Sangoi et al., 2011; 2012). A população de plantas pode estar adequada na média porém sua distribuição heterogênea pode prejudicar a produtividade (Schimandeiro et al., 2006).

População adequada e uniformidade de distribuição longitudinal das plantas de milho na linha é significativa quando se objetiva alcançar alta produtividade. O milho é altamente sensível às variações da população de plantas, ao espaçamento entre linhas, à uniformidade de emergência e à uniformidade de distribuição de plantas na linha, pois o mesmo apresenta limitada plasticidade (Sangoi et al., 2011, 2012). Na cultura do milho é necessário que a planta apresente condições adequadas de interceptação de radiação solar, a qual é função direta da população e da distribuição de plantas na área (Fancelli \& Dourado Neto, 2000).

Quando se pesquisam diferentes mecanismos de distribuição de sementes em diferentes condições técnicas, operacionais e ambientais, supõe-se que a quantificação da média da distância ou a distância média entre as plantas, é importante; entretanto, a distância média não é suficiente para avaliar a qualidade final da instalação do plantio e, neste sentido, a quantificação da variabilidade espacial e a formação de falhas e de plantas duplicadas no sulco de semeadura, também são imprescindíveis.

Um trabalho importante de avaliação tecnológica de semeadoras quanto a regularidade de distribuição longitudinal de sementes, em ensaios de bancada, foi desenvolvido por Kurachi et al. (1989). Esses autores usaram o coeficiente de variação $(\mathrm{CV})$ dos espaçamentos entre as sementes como medida de regularidade; também se enquadraram as distâncias (D) entre as sementes em três classes: duplos para $\mathrm{D}<0,5 \mathrm{Dp}$; aceitáveis para $0,5 \mathrm{Dp}<\mathrm{D}<1,5 \mathrm{Dp}$; falhas para $\mathrm{D}>1,5 \mathrm{Dp}$, em que Dp é a distância recomendada para a cultura.

Silveira et al. (2005) propuseram modificação neste método sendo que as avaliações consistiram no registro da distância entre 25 plantas nas duas linhas centrais de cada unidade experimental, em cada repetição. Os limites de classe adotados foram definidos em relação a um valor de referência $(\mathrm{Dp}=$ $18,52 \mathrm{~cm}$ ) como sendo: duplos para $\mathrm{D}<0,8 \mathrm{Dp}$; aceitáveis para $0,8 \mathrm{D} p<\mathrm{D}<1,2 \mathrm{Dp}$ e falhas para $\mathrm{D}>1,2 \mathrm{Dp}$. Foram computadas as frequências das medidas dentro de cada classe, para fins de análise estatística.

De acordo com Kachman \& Smith (1995) o CV não é adequado para avaliação do desempenho de semeadoras uma vez que a distribuição dos espaçamentos entre plantas, neste caso, não é normal. Apesar disto e de acordo com as normas da ABNT (1994), o CV deve ser obtido levando-se em consideração toda a amostra de espaçamentos. Acredita-se que a medida percentagem de espaçamentos na classe aceitável como variável para ser submetida a uma análise estatística, não expressa adequadamente o valor da unidade experimental e pode ampliar o erro experimental referente à avaliação deste caractere; primeiro, porque são apenas três classes e também porque a determinação dos limites de classe é subjetiva; segundo, se for usar a percentagem da classe dos espaçamentos aceitáveis para a análise, como se deve aproveitar os dados das demais classes? Ainda a distribuição de frequência das distâncias não é necessariamente simétrica.

A definição de uma medida adequada da regularidade do espaçamento entre plantas e do respectivo tamanho ótimo de amostra a ser usada para avaliar as unidades experimentais em experimentos de campo, é aconselhável para a qualificação da pesquisa com semeadoras e demais fatores ambientais que afetam a regularidade no espaçamento e, por consequência, a produtividade das culturas. Embora seja consenso que a variabilidade na distribuição longitudinal de plantas na linha de semeadura do milho pode influenciar as competições intraespecíficas (Brachtvogel et al., 2012) e interespecíficas (Nice et al., 2001) pouco se tem estudado sobre os métodos de avaliar esta regularidade e os fatores que a influenciam.

O objetivo foi obter uma "medida de regularidade" do espaçamento de plantas de milho e o número ótimo de plantas em sequência para estimar a medida de regularidade no espaçamento, em diferentes sistemas de manejo.

\section{Material e Métodos}

O experimento I foi conduzido em Latossolo Vermelho Distroférrico, com textura muito argilosa. Utilizaram-se o delineamento blocos ao acaso, as parcelas subsubdivididas e com quatro repetições. Nas parcelas principais foram casualizados quatro manejos da palha (dessecado, gradeado, rolado e triturado), nas subparcelas dois mecanismos sulcadores (disco duplo e haste sulcadora) e nas subsubparcelas (unidade experimental, UE) duas velocidades contrastantes da máquina $\left(4,5\right.$ e $\left.7,0 \mathrm{~km} \mathrm{~h}^{-1}\right)$.

A área foi dividida em quatro blocos casualizados totalizando 64 unidades experimentais, cada qual com área de $64 \mathrm{~m}^{2}$ (3,2 x $\left.20 \mathrm{~m}\right)$, com espaçamento de $10 \mathrm{~m}$ entre blocos, utilizados para manobra e estabilização da velocidade de trabalho do conjunto trator semeadora-adubadora.

A semeadura do milho foi realizada em 28 de outubro de 2010, utilizando-se uma semeadora-adubadora de precisão para semeadura direta com dosador de sementes do tipo discos horizontais. Utilizou-se o híbrido DKB 240 YG, com $85 \%$ de germinação e $98 \%$ de pureza mínima, o qual é um híbrido simples, de ciclo precoce. O híbrido foi semeado num espaçamento de $0,80 \mathrm{~m}$ entre linhas e na densidade de semeadura de aproximadamente 62.500 sementes ha $^{-1}$. A máquina foi regulada para distribuir as sementes em espaçamento regular de $0,20 \mathrm{~m}$. Foram avaliadas as distâncias entre 40 plantas em cada uma das UE.

O experimento II foi conduzido em Latossolo Vermelho Alumino férrico típico, de textura argilosa. Foram utilizados o delineamento de blocos ao acaso, as parcelas subdivididas e com quatro repetições. Nas parcelas principais foram casualizadas quatro alturas de pastejo dos animais (entrada dos animais e saída dos animais das parcelas) com $0,25 \mathrm{x}$ $0,05 \mathrm{~m} ; 0,30 \times 0,10 \mathrm{~m} ; 0,35 \times 0,15 \mathrm{~m}$ e sem pastejo enquanto 
nas subparcelas (UE) foram casualizados dois mecanismos sulcadores (disco duplo e haste sulcadora) com velocidade de $4,5 \mathrm{~km} \mathrm{~h}^{-1}$.

A área foi dividida em quatro blocos casualizados totalizando 32 unidades experimentais, cada qual com área de $95 \mathrm{~m}^{2}(4,1 \times 23 \mathrm{~m})$. A semeadura da cultura do milho foi realizada em 14/10/2009 utilizando-se uma semeadoraadubadora de precisão para plantio direto com dosador de sementes do tipo discos horizontais. O híbrido utilizado foi Pioneer 30R50, com $85 \%$ de germinação e $98 \%$ de pureza mínima, semeado num espaçamento de $0,83 \mathrm{~m}$ entre linhas e numa densidade de semeadura de 65.100 sementes ha-1 ${ }^{-1} \mathrm{Na}$ semeadura máquina foi regulada para distribuir as sementes no espaçamento regular de $0,185 \mathrm{~m}$. Foram avaliadas as distâncias entre 18 plantas em cada uma das UE.

Para fins de caracterização da regularidade de espaçamento entre plantas foram medidas, em cada uma das UE, as distâncias entre as plantas consecutivas; em princípio, a estimativa da variância da distância entre $\mathrm{n}$ plantas consecutivas é uma medida da regularidade. Espaçamentos iguais ou semelhantes entre plantas resultam em variância nula ou muito pequena. Considerando que em experimentos de campo o número de plantas por UE nem sempre é o mesmo, torna-se necessário padronizar a medida de regularidade (MR) em função do número de distâncias entre plantas consecutivas (n). Esta padronização, proposta neste estudo, pode ser feita utilizandose a expressão $\operatorname{MR}(n)=n^{2} S_{n}{ }^{2} / \sigma_{n}{ }^{2}$, em que $S_{n}{ }^{2}$ é a estimativa da variância das distâncias entre as $n$ plantas e $\sigma_{n}^{2}$ é a variância dos n primeiros números positivos inteiros tidos como padrão de regularidade, ou seja, $\sigma_{n}^{2}=\{(n+1) /[12(n-1)]\}[2 n(2 n+$ $1)-3 n(n+1)]$, com a restrição de pelo menos três plantas ou duas distâncias $(n \geq 3)$ por UE. O valor da $M R(n)$ foi estimado para as primeiras $n=10, n=15, n=20, n=25, n=30, n=35$ e $\mathrm{n}=40$ distâncias entre as plantas disponíveis em todas as UE do ensaio de manejo; enfim, no ensaio de pastejo os valores de n foram: 5, 10, 15 e 18 plantas, para cada UE.

A partir das estimativas MR, para os diferentes números de plantas consecutivas, das médias das distâncias entre as n plantas e da produtividade de grãos de cada uma das UE's, foram procedidos a análise de variância e os testes de hipóteses. Estimativas por intervalo, usando a metodologia de reamostragem bootstrap (Ferreira, 2005), foram usadas para comparar médias de tratamentos pelo aplicativo BioEstat 5.3; para as análises, também foram usados os aplicativos Genes (Cruz, 2006) e a planilha Excel.

\section{Resultados e Discussão}

Para os resultados do estudo do manejo, sulcador e velocidade, a estimativa da média das distâncias entre as plantas $(0,201 \mathrm{~m})$ esteve próximo do previsto na regulagem da máquina $(0,200 \mathrm{~m})$. A quantidade de sementes liberada pela semeadora foi adequada e a germinação foi próxima aos $100 \%$, em virtude das boas condições do solo e clima, para tal fim.

Os quatro manejos de palhada e os dois mecanismos sulcadores não afetaram a média das distâncias entre as plantas e, tampouco, a regularidade das distâncias (Tabela 1); a velocidade de operação da máquina teve, no entanto, efeito significativo sobre a média da distância entre as plantas e sobre
Tabela 1. Resumo de análise de variância referentes às medidas de distância média entre plantas de milho, a medida de regularidade (MR) das distâncias e a produtividade de grãos (Prod.)

\begin{tabular}{lcccc}
\hline \multirow{2}{*}{ FV } & GL & \multicolumn{3}{c}{ Quadrado médio } \\
\cline { 3 - 5 } Bloco $(B)$ & 3 & Distância & MR & Prod. \\
Manejo (M) & 3 & 1,185 & 359163 & 1,0507 \\
Erro (M) & 9 & 0,737 & $271465^{\text {ns }}$ & $0,7286^{\text {ns }}$ \\
Sulcador $(\mathrm{S})$ & 1 & $0,072^{\text {ns }}$ & 332170 & 1,0141 \\
M x S & 3 & $2,455^{\text {ns }}$ & $315290^{\text {ns }}$ & $0,2706^{\text {ns }}$ \\
Erro (S) & 12 & 1,649 & 480285 & $0,1089^{\text {ns }}$ \\
Velocidade $(\mathrm{V})$ & 1 & $7,182^{*}$ & $1930057^{\text {* }}$ & 0,7053 \\
M x V & 3 & $1,077^{\text {ns }}$ & $197399^{\text {ns }}$ & $0,9243^{\text {ns }}$ \\
S x V & 1 & $0,342^{\text {ns }}$ & $165053^{\text {ns }}$ & $0,0001^{\text {ns }}$ \\
M x S x V & 3 & $0,568^{\text {ns }}$ & $51545^{\text {ns }}$ & $1,2843^{\text {ns }}$ \\
Erro (V) & 24 & 0,9822 & 207796 & 1,32098 \\
Média & - & 20,10 & 908,2 & 11,361 \\
CV\% & - & 4,9 & 50,2 & 10,1 \\
\hline
\end{tabular}

*Significativo pelo teste $F(p<0,05)$; " ns não significativo

a regularidade das distâncias, sem interagir com os demais efeitos. Observa-se ainda que a produtividade de grãos não foi afetada pelos diferentes manejos, sulcadores, velocidades nem pelas respectivas interações.

$\mathrm{Na}$ Tabela 2 observa-se que a maior velocidade $(7,0 \mathrm{~km}$ $\mathrm{h}^{-1}$ ) determinou também maior média da distância entre as plantas e maior heterogeneidade (maior MR) nas distâncias entre as plantas. Este resultado pode estar atribuído à maior velocidade periférica do disco dosador reduzindo a capacidade de enchimento do disco e fazendo com que ocorra diminuição da porcentagem de espaçamentos aceitáveis (Mahl et al., 2004; Garcia et al., 2006).

Dias et al. (2009) encontraram, ao usar o desvio médio para expressar os efeitos de velocidades de operação $(3,5$; 4,3; 5,5 e 7,0 $\mathrm{km} \mathrm{h}^{-1}$ ) e densidades de semeadura (três, cinco e sete sementes $\mathrm{m}^{-1}$ ) sobre a regularidade de distribuição de sementes para a cultura do milho, resultados semelhantes aos deste trabalho. Os autores verificaram que as densidades de três e sete sementes $\mathrm{m}^{-1}$ apresentaram elevação no desvio médio com aumento da velocidade de semeadura. Por outro lado, para a densidade de cinco sementes $\mathrm{m}^{-1}$, o comportamento foi de redução do desvio médio até a velocidade de 5,0 $\mathrm{km} \mathrm{h}^{-1} \mathrm{e}$ elevação do desvio médio a partir desta velocidade.

A estimativa do coeficiente de correlação (Tabela 2) positivo e significativo $(r=0,71 ; p<0,01)$ confirma que, quanto maior a média da distância entre as plantas (maior velocidade) maior também é a heterogeneidade (maior MR) da distância entre as plantas.

Para os resultados do estudo das intensidades de pastejo e sulcador (experimento II), a estimativa da média das distâncias

Tabela 2. Distâncias médias entre plantas de milho e da medida de regularidade (MR) das distâncias relacionadas à velocidade de operação de semeadura

\begin{tabular}{ccc}
\hline $\begin{array}{c}\text { Velocidade } \\
\left(\mathbf{k m ~ h}^{-1}\right)\end{array}$ & $\begin{array}{c}\text { Distância } \\
(\mathbf{c m})\end{array}$ & MR \\
4,5 & $19,77 \mathrm{~b}$ & $734,5 \mathrm{~b}$ \\
7,0 & $20,44 \mathrm{a}$ & $1081,8 \mathrm{a}$ \\
Coeficiente de correlação de Pearson (Dist x MR) & $=0,71(\mathrm{p}<0,01 ; \mathrm{n}=64)$ \\
\hline
\end{tabular}

*Médias de velocidades seguidas por mesma letra não diferem pelo teste de Duncan ( $p$ $=0,05)$ 
entre as plantas $(0,1892 \mathrm{~m})$ também se manteve próximo ao previsto na regulagem da máquina $(0,1850 \mathrm{~m})$. A máquina depositou no solo quantidade adequada de sementes e a germinação foi próxima a $100 \%$. Não houve efeito significativo para as intensidades de pastejo e os sulcadores, quanto à distância média entre as plantas, MR e produtividade de grãos (Tabela 3); no entanto, a interação pastejo x sulcador foi significativa $(\mathrm{p}<0,05)$ para a distância média entre as plantas.

Tabela 3. Resumo de análise de variância referentes à distância média entre plantas de milho, à medida de regularidade $(M R)$ das distâncias e à produtividade de grãos (Prod.)

\begin{tabular}{lcccc}
\hline \multirow{2}{*}{ FV } & \multirow{2}{*}{ GL } & \multicolumn{3}{c}{ Quadrado médio } \\
\cline { 3 - 5 } Bloco $(\mathrm{B})$ & 3 & Distância & MR & Prod. \\
Pastejo $(\mathrm{P})$ & 3 & 0,573 & 273805 & 0,3372 \\
Erro $(\mathrm{P})$ & 9 & $4,920^{\text {ns }}$ & $43638^{\text {ns }}$ & $0,4360^{\text {ns }}$ \\
Sulcador $(\mathrm{S})$ & 1 & $3,465^{\text {ns }}$ & 93159 & 1,7989 \\
P x S & 3 & $4,297^{*}$ & $162299^{\text {ns }}$ & $0,0077^{\text {ns }}$ \\
Erro(S) & 12 & 0,987 & 103255 & $0,2795^{\text {ns }}$ \\
Média & - & 18,92 & 579,7 & 13,8276 \\
CV\% & - & 5,2 & 55,4 & 4,7 \\
\hline
\end{tabular}

${ }^{*}$ Significativo pelo teste $F(p<0,05)$; ns não significativo

$\mathrm{Na}$ condição sem pastejo o mecanismo disco duplo teve maior distância média entre as plantas, quando comparado com o mecanismo de haste sulcadora (Tabela 4). Devido provavelmente à maior quantidade de material vegetal presente sobre o solo na condição sem pastejo, é que o disco duplo não foi tão eficiente na deposição das sementes para a germinação. A estimativa do coeficiente de correlação de Pearson, positiva e significativa $(\mathrm{r}=0,62 ; \mathrm{p}<0,01)$ confirma que quanto maior a média da distância entre as plantas maior também é a heterogeneidade (maior MR) da distância entre as plantas.

Quanto maior for a medida de regularidade (MR) significativamente menor será a produtividade $(\mathrm{r}=-0,24 ; \mathrm{p}<$ $0,05)$ no estudo do manejo não havendo relação significativa $(\mathrm{r}=0,01)$ no estudo do pastejo. Espera-se que, com este resultado, lavouras com maior heterogeneidade na distribuição das plantas tenham menor produtividade. Esta expectativa é confirmada nos trabalhos desenvolvidos por Bitencourt et al. (2008) e Sangoi et al. (2012) os quais constataram decréscimos no rendimento de grãos do milho ocasionados pelo aumento da irregularidade da distribuição espacial das plantas na linha de semeadura. Mello et al. (2007) entretanto, verificaram, ao avaliar a produtividade de dois híbridos de milho (simples e duplo) em velocidades $\left(5,4,6,8\right.$ e $\left.9,8 \mathrm{~km} \mathrm{~h}^{-1}\right)$ em solo convencional, que o aumento da velocidade causou menor

Tabela 4. Distâncias entre as plantas de milho sob dois mecanismos sulcadores (Disco e Haste) e diferentes manejos de pastejo (altura de entrada x altura de saída dos animais)

\begin{tabular}{ccc}
\hline Pastejo & Disco duplo & Haste sulcadora \\
$25 \times 5 \mathrm{~cm}$ & $19,4 \mathrm{a}^{*}$ & $19,3 \mathrm{a}$ \\
$30 \times 10 \mathrm{~cm}$ & $19,1 \mathrm{a}$ & $18,4 \mathrm{a}$ \\
$35 \times 15 \mathrm{~cm}$ & $18,2 \mathrm{a}$ & $18,9 \mathrm{a}$ \\
Sem pastejo & $20,3 \mathrm{a}$ & $17,7 \mathrm{~b}$ \\
\hline
\end{tabular}

* Médias seguidas por mesma letra, na horizontal, não diferem pelo teste de Duncan $(p=0,05)$ percentagem de espaçamentos normais entre as sementes, menor produtividade de grãos para o híbrido simples mas não interferiu na produtividade do híbrido duplo.

Em relação aos dois estudos, a distância média entre as plantas foi coerente com a regulagem das máquinas. A medida de regularidade $(\mathrm{MR})$ da distância entre as plantas de todas as UE's no estudo do manejo $(M R=908,2)$ e de todas as UE's no estudo do pastejo $(\mathrm{MR}=579,7)$ difere porque as estimativas por intervalo bootstrap ( $1-\mathrm{p}=0,95 ; 5000$ reamostragens) não são coincidentes (Ferreira, 2005); usando o aplicativo BioEstat, ou seja: para $\mathrm{P}($ Limite inferior $<\mathrm{MR}<$ Limite superior $)=0,95$, tem-se que $\mathrm{P}(792,4<\mathrm{MR}<1023,5)=0,95$ para o ensaio de manejo e $\mathrm{P}(473,9<\mathrm{MR}<670,8)=0,95$ para o ensaio de pastejo. As estimativas por intervalo para MR podem ser utilizadas para validar ou não a "qualidade de uma semeadora". Pode-se determinar que se o intervalo de confiança contém o valor preconizado pelo fabricante ou o recomendado para a cultura, ter-se-á uma semeadora adequada.

As estimativas do coeficiente de variação referentes às três variáveis analisadas, foram semelhantes nos dois estudos (Tabelas 1 e 3). A medida de regularidade tem estimativa de $\mathrm{CV}$ maior o que pode ser interpretado como medida (MR) boa para captar a variação ambiental e, por consequência, quando for o caso, significância dos efeitos dos tratamentos.

Nos dois estudos o coeficiente de correlação de Pearson entre MR e $n$ varia de $r=-0,89$ até $r=0,91$ usando como pares de dados as diferentes unidades experimentais; não há, portanto, uma regra de relação entre o valor da estimativa de MR e o número de plantas avaliadas para determinação da MR. Verifica-se, com isto, que a MR independe do número de plantas (tamanho da amostra) usadas para medir as distâncias entre as mesmas. No entanto, estimando MR para diferentes números de plantas consecutivas (n) e se procedendo à análise de variância para o caractere MR pelos mesmos modelos nos dois ensaios (Tabelas 1 e 3) o coeficiente de variação do erro experimental decresce com o aumento do número de plantas (Tabela 5).

Este decréscimo pode ser descrito pelo modelo potência: $\mathrm{CV}=297,53 / \mathrm{n}^{0,5006}\left(\mathrm{r}^{2}=76,2 \%\right)$ no ensaio de manejo e CV $=146,24 / \mathrm{n}^{0,3584}\left(\mathrm{r}^{2}=93,1 \%\right)$ no ensaio de pastejo. Com este modelo $\left(\mathrm{CV}=\mathrm{A} / \mathrm{n}^{\mathrm{B}}\right)$ é possível estimar não apenas o número ótimo de plantas consecutivas $\left(\mathrm{n}_{\mathrm{o}}\right)$ mas também a medida de

Tabela 5. Média, valor mínimo e máximo e coeficiente de variação do erro experimental $(\mathrm{CVe})$ referentes a medida de regularidade $(M R)$ da distância entre as plantas para diferentes número de plantas $(\mathrm{n})$ avaliadas na fileira

\begin{tabular}{|c|c|c|c|c|}
\hline $\mathbf{n}$ & Média & Mínimo & Máximo & CVe (\%) \\
\hline & \multicolumn{4}{|c|}{ Ensaio de manejos } \\
\hline 10 & 1023,4 & 128,0 & 5183,5 & 102,2 \\
\hline 15 & 919,9 & 125,0 & 3658,9 & 80,1 \\
\hline 20 & 923,4 & 161,1 & 2824,0 & 59,3 \\
\hline 25 & 905,5 & 264,7 & 2326,2 & 51,9 \\
\hline 30 & 884,6 & 242,3 & 2220,1 & 46,3 \\
\hline 35 & 926,1 & 272,1 & 4437,8 & 62,0 \\
\hline \multirow[t]{2}{*}{40} & 908,2 & 299,2 & 3938,7 & 50,2 \\
\hline & \multicolumn{4}{|c|}{ Ensaio de pastejos } \\
\hline 5 & 434,3 & 37,0 & 2097,0 & 84,4 \\
\hline 10 & 545,0 & 73,2 & 1716,5 & 61,3 \\
\hline 15 & 563,3 & 97,2 & 1370,9 & 52,8 \\
\hline 18 & 579,7 & 89,8 & 1420,7 & 55,4 \\
\hline
\end{tabular}


regularidade das distâncias, segundo aplicações do método da máxima curvatura modificada (Lorentz et al., 2010; Santos et al., 2012):

$$
n_{o}=\left[A^{2} B^{2} \frac{(2 B+1)}{(B+2)}\right]^{1 /(2 B+2)}
$$

ou seja

$$
\mathrm{n}_{\mathrm{o}}=\left[297,53^{2} \times 0,5006^{2} \frac{(2 \times 0,5006+1)}{(0,5006+2)}\right]^{1 /(2 \times 0,5006+2)}
$$

$\mathrm{n}_{\mathrm{o}}=26$ no ensaio de manejo

$\mathrm{n}_{\mathrm{o}}=16$ no ensaio de pastejo

Desta forma, ao se usar mais de $n_{\mathrm{o}}=26$ plantas, no estudo de manejo e mais de $n_{o}=16$ plantas, no estudo de pastejo, não haverá redução expressiva no coeficiente de variação experimental (CVe, medida de precisão experimental). Além disto, com $n_{o}=25$ ou mais plantas constatou-se, neste estudo, um efeito significativo entre as médias da MR referentes às velocidades no ensaio de manejo (resultados não apresentados). Com o aumento de $\mathrm{n}_{\mathrm{o}}$, as estimativas de MR tendem ao valor obtido com todas as distâncias entre as plantas e a amplitude (valor máximo menos valor mínimo) diminui. Pode-se inferir que a precisão da estimativa de MR aumenta com o aumento de $n$, num limite menor ao praticado nos dois estudos ( $\mathrm{n}=$ 40 e $\mathrm{n}=18$; no estudo de manejo e pastejo, respectivamente).

Visando à melhor compreensão da estimativa MR, a formulação (teórica) de diferentes casos de falhas, numa sequência de seis plantas, está apresentada na Tabela 6. Em todos os casos, a média da distância entre as plantas é a mesma, $20 \mathrm{~cm}$; no caso 1, totalmente regular (homogêneo) a estimativa de MR é nula e no caso 2, com desvio de $2 \mathrm{~cm}$ para mais de um lado e, consequentemente, para menos do outro lado (para manter a média), a estimativa do desvio da média em percentagem (D\%) é: $\mathrm{D} \%=100(2) / 20=10 \%$, e assim para os demais casos. Desta forma e estabelecendo uma relação entre MR e D\% pode-se ter uma ideia da percentagem média do desvio nos espaçamentos. Esta relação é perfeita (coeficiente de determinação igual a 1) com o seguinte modelo: $\mathrm{D} \%=1,42378$ $\mathrm{MR}^{0,5}$. Esta relação não se altera com a variação do número de plantas avaliadas, porque a MR está padronizada em relação ao número de plantas.

Tabela 6. Distâncias (teóricas) entre plantas, média das distâncias, medida de regularidade (MR) para $\mathrm{n}=6$ plantas

\begin{tabular}{|c|c|c|c|c|c|c|c|c|c|}
\hline \multirow{2}{*}{ Caso } & \multicolumn{6}{|c|}{ Plantas } & \multirow[b]{2}{*}{ Média } & \multirow{2}{*}{ MR } & \multirow{2}{*}{ D\% } \\
\hline & 1 & 2 & 3 & 4 & 5 & 6 & & & \\
\hline 1 & 20 & 20 & 20 & 20 & 20 & 20 & 20 & 0,0 & 0 \\
\hline 2 & 18 & 22 & 18 & 22 & 18 & 22 & 20 & 49,4 & 10 \\
\hline 3 & 16 & 24 & 16 & 24 & 16 & 24 & 20 & 197,5 & 20 \\
\hline 4 & 14 & 26 & 14 & 26 & 14 & 26 & 20 & 444,3 & 30 \\
\hline 5 & 12 & 28 & 12 & 28 & 12 & 28 & 20 & 789,9 & 40 \\
\hline 6 & 10 & 30 & 10 & 30 & 10 & 30 & 20 & 1234,3 & 50 \\
\hline 7 & 8 & 32 & 8 & 32 & 8 & 32 & 20 & 1777,4 & 60 \\
\hline 8 & 6 & 34 & 6 & 34 & 6 & 34 & 20 & 2419,2 & 70 \\
\hline 9 & 4 & 36 & 4 & 36 & 4 & 36 & 20 & 3159,8 & 80 \\
\hline 10 & 2 & 38 & 2 & 38 & 2 & 38 & 20 & 3999,1 & 90 \\
\hline
\end{tabular}
e desvio da média em percentagem ( $D \%)$
No estudo de manejo a média de $\mathrm{MR}=908,2$ resulta em $\mathrm{D} \%=1,42378(908,2)^{0,5}=42,9 \%$ (desvio da média em percentagem). Considerando, no mesmo estudo, que a média geral das distâncias foi igual a $20,10 \mathrm{~cm}$, tem-se que o desvio médio é igual a $\mathrm{D} \%=42,9(20,10) / 100=8,62 \mathrm{~cm}$ para menos e para mais em relação à média geral das distâncias $(20,10$ $\mathrm{cm})$ ou seja, as distâncias variam entre $11,48 \mathrm{~cm}(20,10-8,62$ $\mathrm{cm})$ até $28,72 \mathrm{~cm}(20,10+8,62 \mathrm{~cm})$. O valor do desvio médio $(8,62 \mathrm{~cm})$ parece ser baixo e possivelmente a causa da não significância entre os tratamentos de manejo e de sulcador. No estudo do pastejo, com média geral de $M R=579,7$, o valor $\mathrm{D} \%=1,42378(579,7)^{0,5}=34,3 \%$, mostra menor magnitude da heterogeneidade das distâncias entre as plantas. Em relação à média geral das distâncias $(18,92 \mathrm{~cm})$ tem-se $6,49 \mathrm{~cm}$ de desvio médio das distâncias entre as plantas.

Considerando as estimativas por intervalo bootstrap (Ferreira, 2005): $\mathrm{P}(792,4<\mathrm{MR}<1023,5)=0,95$ para o ensaio de manejo e $\mathrm{P}(473,9<\mathrm{MR}<670,8)=0,95$ para o ensaio de pastejo, é possível estimar os limites (inferior e superior) do mesmo intervalo de confiança, usando a relação $\mathrm{D} \%=1,42378 \mathrm{MR}^{0,5}$. No caso do ensaio de manejo: $\mathrm{P}\left(1,42378(473,9)^{0,5}<\mathrm{D} \%<\right.$ $\left.1,42378(670,8)^{0,5}\right)=\mathrm{P}(30,99<\mathrm{D} \%<36,87)=0,95$. Assim, com uma confiança de $95 \%$, o desvio médio no espaçamento entre as plantas está entre 30,99 e 36,87\%; desta forma, para fins de aferir a qualidade das máquinas de distribuição de sementes ou plantas, a campo ou em bancadas experimentais, é possível usar valores obtidos desta forma (limites de D\%) para validar o desempenho prometido pelo fornecedor ou adequado para a cultura praticada.

\section{Conclusões}

1. A estatística denominada "medida de regularidade" é adequada para avaliar a exatidão de distribuição (regularidade) das sementes ou plantas de milho podendo ser aplicada nos casos de laudo técnico de funcionamento de semeadoras; pode ser usada, também, para avaliar o efeito de diferentes manejos e operações de máquinas na produtividade de milho.

2. Para estimar a medida de regularidade é suficiente usar as medidas das distâncias entre 26 plantas no estudo de manejo de palha e 16 plantas no estudo do pastejo sendo, possível, ainda, sua estimativa por intervalo do desvio médio das distâncias entre as plantas.

3. O aumento da velocidade da operação de semeadura resulta em maior distância média entre as plantas e maior medida de regularidade na distância entre as plantas de milho.

\section{Agradecimentos}

Ao $\mathrm{CNPq}$ (Bolsa de Produtividade em Pesquisa), à Fundação Araucária (Bolsa de Produtividade em Pesquisa) e à CAPES (Edital 6/2012, PVNS).

\section{Literatura Citada}

ABNT - Associação Brasileira de Normas Técnicas. Projeto de norma 04:015.06-004 - semeadoras de precisão - ensaio de laboratório - Método de ensaio. São Paulo: ABNT 1994. 26p. 
Bitencourt, R.; Tavares, C. A.; Foralosso, A. A.; Viganó, J. P.; Oliveira, L. G. de.; Duarth, M.; Primo, M. A.; Soncela, R.; Silva, S. de L.; Silva, T. R. B. da. Influência da velocidade de deslocamento da semeadora, com hastes sulcadoras na produtividade do milho. Cultivando o Saber, v.1, p.24-33, 2008.

Brachtvogel, E. L.; Pereira, F. R. S.; Cruz, S. C. S.; Abreu, M. L.; Bicudo, S. J. População, arranjo de plantas uniforme e a competição intraespecífica em milho. Revista Trópica - Ciências Agrárias e Biológicas, v.6, p.75-80, 2012.

Cruz, C. D. Programa GENES: Estatística experimental e matrizes. Viçosa: UFV, 2006. 285p.

Dias, V. O.; Alonço, A. S; Baumhardt, U. B.; Bonotto, G. J. Distribuição de sementes de milho e soja em função da velocidade e densidade de semeadura. Ciência Rural, v.39, p.1721-1728, 2009. http:// dx.doi.org/10.1590/S0103-84782009005000105

Fancelli, A. L.; Dourado Neto, D. Fisiologia da produção e aspectos básicos de manejo para alto rendimento. In: Sandini, I. E.; Fancelli, A. L. Milho: Estratégias de manejo para a região Sul. Guarapuava: Fundação Agrária de Pesquisa Agropecuária, 2000. Cap.5, p.103-115.

Ferreira, D. F. Estatística básica. Lavras: Editora UFLA, 2005. 664p.

Garcia, L. C.; Jasper, R.; Jasper, M.; Fornari, A. J. Blum, J. Influência da velocidade de deslocamento na semeadura do milho. Engenharia Agrícola, v.26, p.520-527, 2006. http://dx.doi.org/10.1590/S010069162006000200021

Kachman, S. D.; Smith, J. A. Alternative measures of accuracy in plant spacing for planters using single seed metering. Transactions of the ASAE, v.38, p.379-387, 1995. http://dx.doi. org/10.13031/2013.27843

Kurachi, S. A.; Costa, J. A. S.; Bernardi, J. A.; Coelho, J. L. D.; Silveira, G. M. Avaliação tecnológica de semeadoras e/ou adubadoras: tratamento de dados de ensaios e regularidade de distribuição longitudinal de sementes. Bragantia, v.48, p.249-262, 1989. http:// dx.doi.org/10.1590/S0006-87051989000200011

Lorentz, L. H.; Boligon, A. A.; Storck, L.; Lúcio, A. D.. Plot size and experimental precision for sunflower production. Scientia Agrícola, v.67, p.408-413, 2010. http://dx.doi.org/10.1590/S010390162010000400005
Mahl, D.; Gamero, C. A.; Benez, S. H.; Furlani, C. E. A.; Silva, A. R. B. Demanda energética e eficiência da distribuição de sementes de milho sob variação de velocidade e condição de solo. Engenharia Agrícola, v.24, p.150-157, 2004. http://dx.doi.org/10.1590/S010069162004000100017

Mello, A. J. R.; Furlani, C. E. A.; Silva, R. P.; Lopes, A.; Borsatto, E. A. Produtividade de híbridos de milho em função da velocidade de semeadura. Engenharia Agrícola, v.27, p.479-486, 2007. http:// dx.doi.org/10.1590/S0100-69162007000300017

Nice, G. R. W.; Buehring, N. W.; Shaw, D. R. Sicklepod (Senna obtusifolia) response to shading, soybean (Glycine max) row spacing, and population in three management systems. Weed Technology, v.15, p.155-162, 2001. http://dx.doi. org/10.1614/0890-037X(2001)015[0155:SSORTS]2.0.CO;2

Sangoi, L.; Schmitt, A.; Vieira, J.; Picoli Jr. G. J.; Souza, C. A.; Casa, R. T.; Schenatto, D. E.; Giordani, W.; Boniatti, C. M.; Machado, G. C.; Horn, D. Variabilidade na distribuição espacial de plantas na linha e rendimento de grãos de milho. Revista Brasileira de Milho e Sorgo, v.11, p.268-277, 2012.

Sangoi, L.; Schweitzer, C.; Silva, P. R. F.; Schmitt, A.; Vargas, V. P.; Casa, R. T.; Souza, C. A. Perfilhamento, área foliar e produtividade do milho sob diferentes arranjos espaciais. Pesquisa Agropecuária Brasileira, v.46, p.609-616, 2011. http://dx.doi.org/10.1590/S0100204X2011000600006

Santos, D.; Haesbaert, F.M.; Lúcio, A.D.; Storck, L.; Cargnellutti Filho, A. Tamanho ótimo de parcela para a cultura do feijão-vagem. Revista Ciência Agronômica, v.43, p.119-128, 2012. http://dx.doi. org/10.1590/S1806-66902012000100015

Schimandeiro, A.; Weirich Neto, P. H.; Gimenez, L. M.; Colet, M. J.; Garbuio, P. W. Distribuição longitudinal de plantas de milho (Zea mays L.) na região dos Campos Gerais, Paraná. Ciência Rural, v.36, p.977-980, 2006. http://dx.doi.org/10.1590/S010384782006000300040

Silveira, J. C. M.; Gabriel Filho, A.; Tieppo, R. C.; Torres, D. G. B.; Baldessin Júnior, A.; Boligon, F. Uniformidade de distribuição de plantas e estande de milho (Zea mays L.) em função do mecanismo dosador de sementes. Acta Scientiarum. Agronomy, v.27, p.467-472, 2005. 